\title{
Urban form and economic sustainability in housing projects
}

\author{
Mohamed Mahmoud Ahmed Abdel Ghaffar and Noha Ahmed Abd El Aziz
}

\author{
* Correspondence: moh88. \\ elsewady@gmail.com \\ Urban Design Department, Faculty \\ of Urban and Regional Planning, \\ Cairo University, Cairo, Egypt
}

\begin{abstract}
Urban areas in metropolitan cities like Cairo suffer from economic, social, and environmental predicaments. Urban economic sustainability is an approach that reforms the urban performance to gain direct benefits such as minimizing costs and maximizing profits and indirect benefits as better social, environmental, and cultural aspects. This research suggests applying such an approach to enhance Egyptian housing projects. The main research question is how to evaluate the economic sustainability of urban forms?. The study presents a "Sustainable Urban Economy model" (SUE model) linking urban fabric, land use pattern, transportation, and street network design with economic sustainability. Research methods and tools include interviews (Delphi method) with 25 urban planning/design and urban economic experts to refine the model. Results show the most effective components of the urban form on economic sustainability (accessibility and degree of permeability, population density, built, and the impact of sub-indicators on the main components. Moreover, results indicate that the seven most influential indicators are the built-up to total space ratio, mixed-use ratio, built-up ratio, population density, floor area ratio, degree of accessibility, and public transportation. Experts suggested values for the seven indicators to measure how the urban form can achieve high economic, environmental, and social performance in the Egyptian context.
\end{abstract}

Keywords: Urban economics, Economic sustainability, Sustainability indicators, Sustainable urban Economy, Urban form

\section{Introduction}

By 2050, two-thirds of all humanity, 6.5 billion people, will live in urban settlements [1]. Due to rising populations and increasing migration, the rapid growth of cities has led to a boom in metropolitan cities, especially in cities in the developing world, such as Egypt. Cairo is the largest metropolitan city in the Arab world, characterized by high pollution, shortage of public services and transportation, poor infrastructure, and the rapid demand for housing. Such uncontrolled demand and feeble regulations resulted in irregular growth, creating slums extending on agricultural land or unsafe zones (cliffs), or resulted in the densification of planned areas, transforming them to unplanned. Both urban patterns caused massive energy consumption, poor waste

(c) The Author(s) . 2021 Open Access This article is licensed under a Creative Commons Attribution 4.0 International License, which permits use, sharing, adaptation, distribution and reproduction in any medium or format, as long as you give appropriate credit to the original author(s) and the source, provide a link to the Creative Commons licence, and indicate if changes were made. The images or other third party material in this article are included in the article's Creative Commons licence, unless indicated otherwise in a credit line to the material. If material is not included in the article's Creative Commons licence and your intended use is not permitted by statutory regulation or exceeds the permitted use, you will need to obtain permission directly from the copyright holder. To view a copy of this licence, visit http://creativecommons.org/licenses/by/4.0/. The Creative Commons Public Domain Dedication waiver (http://creativecommons.org/publicdomain/zero/1.0/) applies to the data made available in this article, unless otherwise stated in a credit line to the data. 
management, lack of services, open green spaces, infrastructure, and public transportation, in addition to a distorted local identity and lack of variety of housing prices and a degraded quality of life. All previous can be labeled under unsustainable urban communities contradicting the sustainable city notion which offers career and business opportunities, safe and affordable housing, public transport, green public spaces, and dynamic economic growth [1-3]. According to UN 2013, cities' sustainability can be conceived by integrating four pillars: social development, economic development, environmental management, and urban governance $[2,3]$.

Meanwhile, local governance in Egyptian cities suffers from a scarcity of public housing funds; therefore, finding an approach to maximize financial performance is needed without compromising environmental and social aspects. For example, raising the densities to optimize land usage may compromise providing open green spaces. Another example is omitting shade trees in streets to reduce cost may affect walkability. From this argument, the research quest starts to explore the concept of economic sustainability and its indicators. Then, it links the concept to the urban form and extracts its indicators and sub-indicators.Indicators would be refined later on, and a final measurable set of indicators would be presented to assess the economic sustainability of the urban form in housing projects.

\section{Economic sustainability}

Economic sustainability refers to practices that support long-term economic growth without negatively impacting the community's social, environmental, and cultural aspects [4]. It is guided and constrained by ecological, social, and economic principles. It services holism, diversity, and interdependence; for example, economic sustainability ensures the extraction of natural materials is less than or equal to the growth of renewable resources, and waste can be assimilated and used productively [5]. Economically sustainable projects differ from projects seeking economic benefits, whereas the second measures their goals in terms of money generated, such as net income, revenues, net cash flow, return on investment or capital saved, and reduced costs [4], (https://www. un.org/en/development/desa/policy/wess/wess_current/wess2013/Chapter3.pdf), while sustainable economic projects pursue fulfilling present financial needs without diminishing future generations' economic needs [6]. Economic sustainability advocates reducing energy consumption, downsizing costs, maximizing economic returns and adding new innovative values (Fig. 1) (https://www.un.org/en/development/desa/policy/wess/ wess_current/wess2013/Chapter3.pdf, [8].

Economic sustainability relies on four principles, growth, development, productivity, and trickle-down $[8,9]$. Some social and ethical values have monetary value, thus can be internalized into the economy. However, others, such as personal relationships and stewardship of clean water, are hard to calculate their economic value. Hicks originated the notion of economic sustainability in value and capital (1939) [8, 9]. Followed him, Goodland, who questioned the feasibility of uncontrolled growth and exponential consumption, he disputed the importance of embracing the forms of capital natural, social and human not only to money $[8,9]$. Although Goodland's argument seems logical, the dilemma occurs when trying apply the concept of economic sustainability to practice in the urban design field, as the application requires fashioned methods to balance between long- and short-term benefits [10]. 


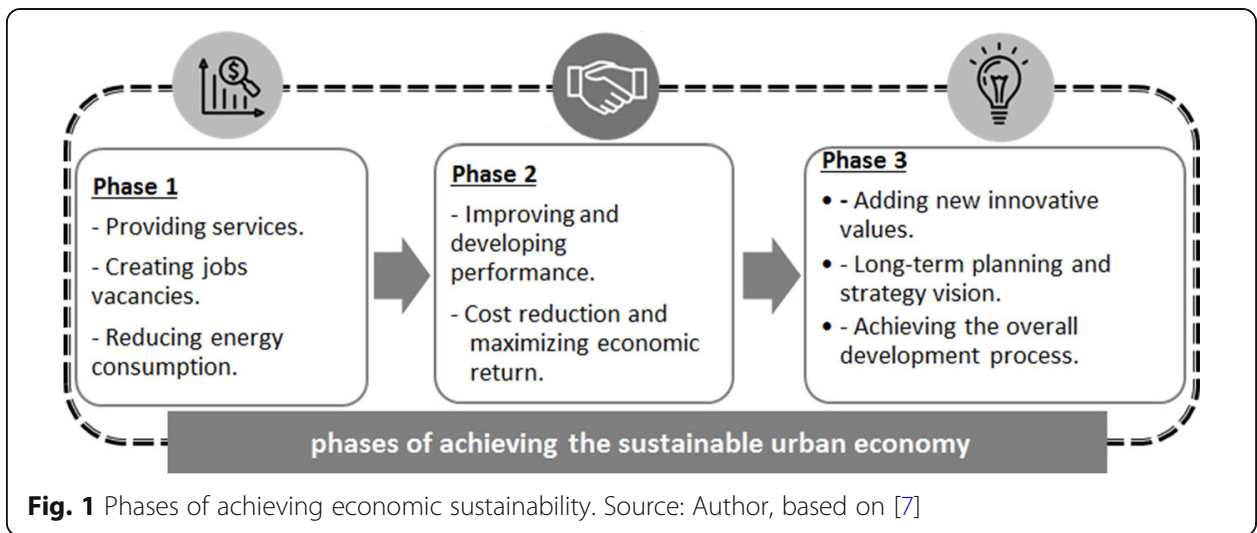

\section{Urban economic sustainability}

After reviewing the notion "economic sustainability" the research seeks to apply the concept on housing projects. Urban economic sustainability is interested in enchaining the project performance by concentrating on direct finial profits and indirect benefits regarding social ties and environmental prospects. In order to extract the criteria representing economic sustainability, indicators from models as Leed, Breeam, Casbee, PCRs, Green Star, Dgnb, and Gprs are visited and analyzed as those models target the same goals as economic sustainability [11]. Moreover, the study included best practices of cities that took initiatives to accomplish urban economic sustainably as a part of perusing a sustainable city such as Masdar City, UAE, Bedenken City, UK [12], and Brazilian City of Curitiba [9]. Their strategies covered social, environmental, institutional, and economic indicators. The strategies utilized the urban components to accomplish sustainable development, primarily an economic one. Some of those strategies included adopting green infrastructure, applying green architecture principles for buildings, diversity of land uses (mixed-use), increasing open green areas, better accessibility and public transportation, availability of public facilities and services, and providing cycle networks [13]. Strategies impacting the natural environment aimed to reduce consumption of drinking water, the use of solar heaters, reducing waste, encouraging recycling, reducing the use of fossil fuels, reducing vehicle movement in the city, and encouraging the use of public transportation. While strategies supporting the economic indicators relied on the use of local building materials, generating clean energy using technology, reducing energy consumption by optimal orientation for buildings and mixing of uses, the use of advanced infrastructure balancing costs and returns [12]. Social indicators were created by providing open green recreational spaces, providing safe pedestrian paths for walking and cycling [13], and enhance policies to give the poor basic services [9] (Table 1).

\section{City urban form}

To link economic sustainability with urban development, the urban form is selected to represent the most prominent components of urban projects. The urban city form was defended in different perspectives by scholars interested in city planning, starting with Lynch 1961. He described the urban form as the physical characteristics that make up built-up areas, including the shape, size, density, and configuration of settlements $[16$, 
Table 1 The initial list of indicators of economic sustainability in cities. Source: Author, based on $[12,14,15]$

\begin{tabular}{ll}
\hline Environmental elements & Economic elements \\
- Protection from pollution and soil protection & - Steady economic growth rates \\
- Protecting ecosystem networks & - Increasing local production \\
- Reducing resource depletion & - Providing job opportunities \\
- Rationalizing energy consumption & - Satisfying investment rates \\
- Reducing heat island phenomenon & - Reducing unemployment rate \\
- Working to increase vegetation cover & \\
- Managing rainwater, water reuse, and avoiding flooding & \\
- Efficiently using and managing waste & \\
Urban elements & Social elements \\
- Green infrastructure availability & - Preserving the legacy and identity \\
- Applying the green architecture principles to the buildings & - Preserving the culture \\
- Suitability of density for the type of use and nature of & - Improving the quality of life and standard of \\
space & living \\
- Mixed-use availability & - Achieving equality and social justice for \\
- Ease of accessibility between the locations & individuals \\
- Availability of services and public facilities & - Diversity in housing prices \\
- Using local building-materials and recycling building & - Maintaining public health \\
materials & - Social interaction and cohesion \\
- Availability of public transportation & - Providing security and safety \\
- Accessing the services & \\
\hline
\end{tabular}

17]. While Spreiregen (1965) added land-form, natural verdure, weather, density, size, and visual aspects $[18,19]$. Shirvani $(1987)$ and Zhu 2008 declared that the urban form is characterized by land use, building mass, circulation system, pedestrian access, open areas, and parking in addition to visual images [20]. Dempsey, N, et al. 2010 stated that the urban form includes five elements accessibility: land use and density, urban layout, transport infrastructure, housing, and building characteristics [21]. The most repetitive elements found in literature reviews are picked for the sack of this study. The four elements representing the urban form are (urban fabric, land uses, densities, and circulation network). Sub-indicators are derived from [12, 14, 22, 23] as a first step to build the SUE model.as shown in Fig. 2.

\section{Linking urban form with economic sustainability}

What are the most effective urban forms in achieving economic sustainability? To answer such a question, national and international literature linking cost, social identity, health, environmental enhancements to the urban form are collected. Nassamat Abdul Qadir (1997), stated the impact of the urban form on cost, as the configuration of paths, affected the cost and maintenance of those paths [24]. Moreover, the length of block affects the economic costs as stated by Caminos, Horacio, and Goethert, Reinhard, 1975 [25]. Blocks with a length greater than $250 \mathrm{~m}$ per hectare have lower economic efficiency, while blocks with a length less than $100 \mathrm{~m}$ are unprofitable and 


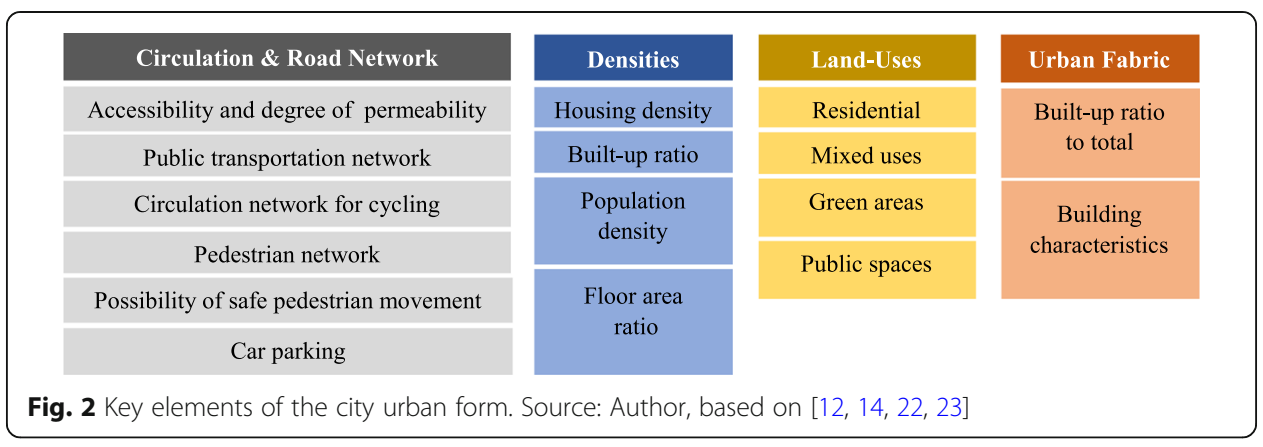

inappropriate for the movement of residents [24]. Another example is applying internal courtyards is found to be more suitable from an economic point of view, as well as pedestrian movement. A study by Yuosry, Mounir, and Barada (1970) in Egypt showed that the urban planning affected the cost of infrastructure. The economic analysis was performed for 400 residential buildings. Three street configurations were presented and assessed, the grid system, the double-line building method and the method of servicing internal courtyards.

The study concluded that using internal courtyards decreased the percentage of roads and corridors to $20 \%$ of the total area; in addition, it provided the highest housing density [26]. All previous examples highlight the direct economic benefit of a specific urban form, while other perspectives were not taken into consideration as indirect impact represented in social and environmental indicators, which is the concern of this research, as shown in Table 2.

\section{Circulation/road network and economic sustainability}

Planning for connectivity, permeability, safety (separate pedestrian from traffic), comfort, including handicap, and the circulation network's attractiveness is essential to achieve economic sustainability, as it would encourage walkability. More walking means better public health and fewer medical bills, in addition to more social interaction [13]. For example, the use of the cul de sac system is not preferred due to its impact on permeability, consequently, and walkability rates. Adopting cycling lanes in the city encourages the use of a clean transportation mode, enhancing economic sustainability [21, 27]. Cycling line rate can be calculated by dividing the cycle route length by total area. An economically sustainable transportation network ought to link all types of land uses through different transportation means [28].

It should be dynamic, affordable, and supports its self-economic wise [27]. The transport system should encourage public transportation and decrease the need to use private cars, enhancing air quality, reducing nonrenewable fuel, and compacting the heat island phenomenon [29]. To control the use of personal vehicles, private car networks and car parking should be limited. LEED, 2009 stated that well-connected areas with public transportation are more sustainable economically [11]. The ratio of public transportation lines can be calculated by dividing the total length of public transportation lines by the total street lengths. At the same time, the degree of connectivity is measured by the number of nodes in the area or the street [21, 27, 29]. 
Table 2 Linking the urban form with economic suitability

\begin{tabular}{|c|c|c|c|c|}
\hline \multirow[t]{2}{*}{ Main indicator } & \multirow[t]{2}{*}{ Sub indicators } & \multicolumn{2}{|l|}{ Indirect } & \multirow{2}{*}{$\begin{array}{l}\text { Direct } \\
\text { Economic }\end{array}$} \\
\hline & & Environmental & $\begin{array}{l}\text { Social/ } \\
\text { heath }\end{array}$ & \\
\hline \multirow[t]{7}{*}{$\begin{array}{l}\text { Circulation and road } \\
\text { network }\end{array}$} & $\begin{array}{l}\text { Accessibility and degree of } \\
\text { permeability }\end{array}$ & $\cdot$ & $\cdot$ & $\cdot$ \\
\hline & Public transportation network & - & & - \\
\hline & $\begin{array}{l}\text { Circulation network for private } \\
\text { vehicles }\end{array}$ & $\cdot$ & & $\cdot$ \\
\hline & Pedestrian network & - & $\cdot$ & \\
\hline & Cycling network & · & $\cdot$ & \\
\hline & $\begin{array}{l}\text { Possibility of safe pedestrian } \\
\text { movement }\end{array}$ & $\cdot$ & $\cdot$ & \\
\hline & Car parking & · & & $\cdot$ \\
\hline \multirow[t]{4}{*}{ Densities } & Housing density & & $\cdot$ & \\
\hline & Built-up ratio & - & & \\
\hline & Population density & & $\cdot$ & - \\
\hline & Floor area ratio & $\cdot$ & $\cdot$ & \\
\hline \multirow[t]{4}{*}{ Land-uses } & Residential & & $\cdot$ & \\
\hline & Mixed uses & $\cdot$ & $\cdot$ & • \\
\hline & Green areas & - & $\cdot$ & \\
\hline & Public spaces & $\cdot$ & $\cdot$ & \\
\hline \multirow[t]{2}{*}{ Urban fabric } & Built-up ratio to total & $\cdot$ & & \\
\hline & Building characteristics & & & - \\
\hline
\end{tabular}

\section{Density and economic sustainability}

Achieving a balance between the vertical condensation and the horizontal expansion and land reserved for transportation networks and movement is essential to achieving the city's economic sustainability. Occupancy ratio (footprint) is an important indicator that can be defined as the total built-up area for the first floor uses divided by the total area [21,29]. There is an inverse relationship between this indicator and the extent of achieving economic sustainability. The smaller the footprint is, the greater the economic sustainability rate. This can be explained as a smaller footprint allows better permeability, airflow, uses less material and energy, less infrastructure, and reduces ecological footprint $[13,21$, $29,30]$.

Population density also has an impact on economic sustainability; the density is calculated by dividing the total population on the area in acres [13]. The higher the density, the greater the percentage of achieving economic sustainability, as higher densities encourage social interaction, create vitality, and provide services at walkable distances, decreasing travel time and pollution related to it.

High population reduces the average costs of the transport network and is more energy-efficient $[13,21,29,30]$. Moreover, the floor area ratio can contribute to achieving economic sustainability as large floor area ratios are associated with more economic sustainably. The floor area ratio is calculated by dividing the gross floor area of a building(s) by the total buildable area of the piece of land upon which it is built [21]. A larger floor area ratio maximizes the economic benefits and land value. Regarding housing density, it is measured by dividing 
home residents' number by the unit area. When it increases, the economic sustainability decreases as crowing, less privacy, and social problems emerge.

\section{Land use and economic sustainability}

Economic sustainable land uses should be combined and mixed with each other, whether on the level of a single building or a group of buildings [31]. The ratio is calculated by dividing the mixed-use area by the total area to get a sense of the degree of mixing. A positive relationship is found between this indicator and the extent to which economic sustainability is achieved. More mixed uses encourage economic investment, promote efficient use of land and infrastructure, enhance vitality, decrease travel time, support social interaction, and provide better chances for job opportunities and services. Furthermore, more mixed uses promote a sense of place and support pedestrian and bicycle travel, resulting in reducing auto dependency. Open space ratio is another indicator; more spaces support social cohesion and relations and promote human wellbeing [11]. Environmentally, green open spaces protect biodiversity, reduce pollution, improve city water management, and mitigate the effects of global warming, which increases the economic sustainably [30]. The percent of green areas in the city can be measured either by dividing their area by total area of the city or by person quota. The last indicator is the residential use, more residential use means more economic sustainability as the possibility of providing a variety of residential levels with different prices prevails $[21,27,28]$.

\section{Urban fabric and economic sustainability}

The urban fabric represents the occupied and vacant land, space, squares, and movement paths [24, 32]. It can be measured by the Compactness Index, which represents the ratios of buildings to spaces [30]. As stated by LEED 2009, the smaller the ratio of buildings to open spaces, the greater the percentage of achieving economic sustainability, as more spaces allow to providing open space and green areas. Major forces affecting urban fabrics are economic factors; these factors include land ownership, land value, cost, financing, and investment patterns.

Previous factors can manipulate the project land use scheme, densities, occupancy percent, the type of the target population, and the percent of parking lots and open spaces. Building characters additionally impact economic sustainability, as the use of local materials, use of energy, water consumption, and utilities impact construction and running cost. Green architecture principles generally support economic sustainability [12-15, 30, 32]. In Table 2, the four main indicators, circulation and road network densities, densities, land-uses urban fabric, and their sub-indicators, are connected with their impact on direct economic profits, in addition to their indirect impact on the natural environment and the social environment.

\section{Methods}

After formulating the main and sub-indicators from literature reviews and good practices, the study started with 17 sub-indicators to be filtered by experts to deduct the final indicators of the proposed sustainable urban economy (SUE) model as shown in Fig. 3. The researchers conducted interviews and questionnaires, including 25 experts 


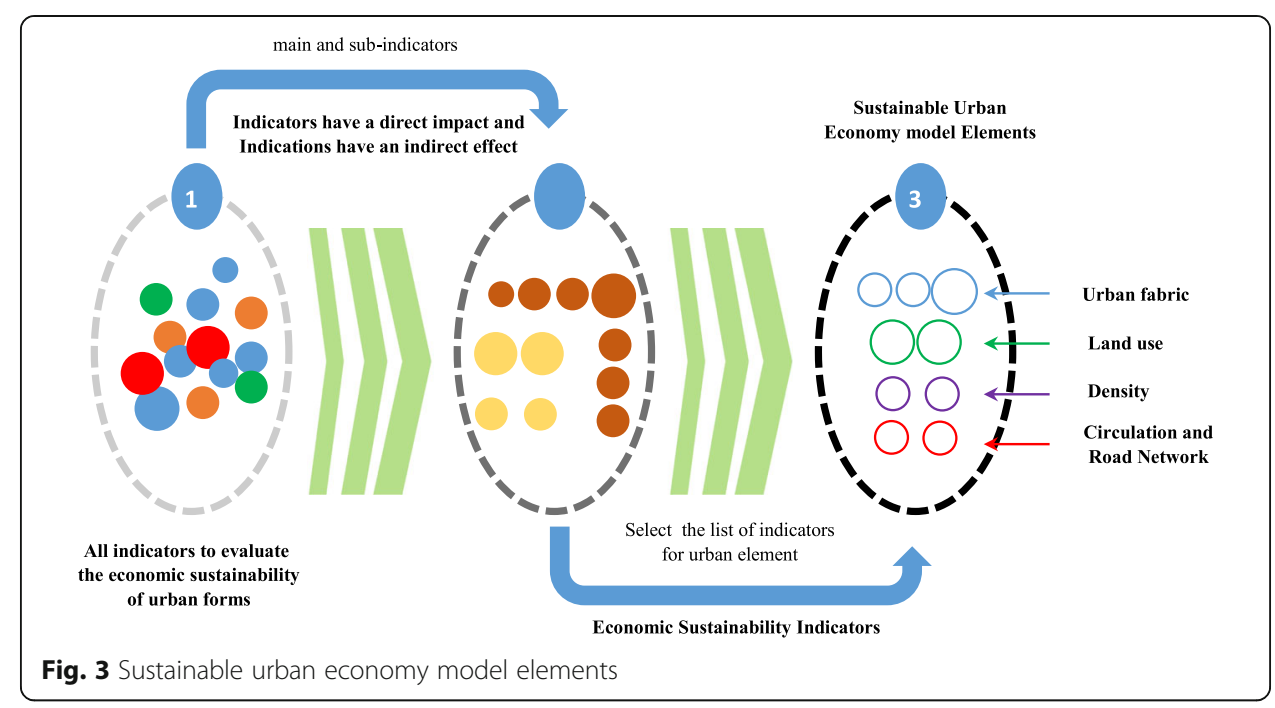

in urban design and urban economic fields. Urban design experts (16 experts) are either academics from the Faculty of Engineering/the Faculty of Urban and Regional Planning, Cairo University, or experts practicing urban planning and design at esteemed engineering consulting firms or governmental institutions. The urban economic consults (9 experts) are either engineers with a solid economic background or academics from the Faculty of Politics and Economics. Experts had to have a minimum of 20 years of experience in the field of specialization.

Delphi method was applied, and the questioner was tested on a group of experts in a pilot study to develop it and make sure that all questions are straight forward. The questioner was conducted in two rounds; the first round aimed at identifying and ranking the indicators affecting the economic sustainability of urban forms. The second round sought to transform the qualitative indicators into measurable indices.

In the first round, the questionnaire included three sections. The first section defined the urban form components and asked experts to suggest a relative weight (divide $100 \%$ between the urban fabric, land use, densities, network of traffic, and roads). In the second section, experts were asked to arrange the sub-indicators according to the degree of their influence on the main category, as well as determining the degree of importance of each sub-indicator on achieving economic sustainability using an ordinal scale from 1 to 5 , where 5 is the most important. Finally, experts had to rank the five most influential indicators that affect the economic sustainability in urban projects. At the end of the questionnaire, a space was left for the expert to suggest other indicators he saw important. In the second round, experts were asked to suggest values for each indicator. On a scale of 3 , the value is either unsustainable or partially sustainable, or sustainable. Collected data were coded, classified, and analyzed using the statistical analysis program (SPSS). The MODE/frequency methods are analyzed to capture expert opinions' repeated values to formulate the final model.

\section{Limitations}

This study is limited by time and resources only 25 experts working in Great Cairo Region were interviewed. The study chose to concentrate on just four criteria of the urban 
form. The values suggested in this study are more a guide than a rubric as areas' natural and social environments can significantly affect these values.

\section{Results}

\section{Round 1: formulating the final indicators of the sue model}

After analyzing the questionnaires, the results show the relative importance of the urban form components regarding economic sustainability as following (land use $33.3 \%$, circulation and road network $24.7 \%$, density $22.7 \%$, urban fabric $19.3 \%$ ) as in Fig. 4.

Public transport network, communication and permeability, built-up area, mixed-use ratio, and land occupancy are the sub-indicators that scored from medium to high impact on their main category. Expects ranked mixed-use ratio, urban fabric, degree of connectivity and permeability, population density, and built-up ratio as the most essential five indicators in measuring the urban form economic sustainability. Meanwhile, the least impactful indicators were the (cycling network, the density of residential units, private transportation network, and pedestrian network) (Fig. 5).

Experts were asked to pick the five most important indicators to evaluate economic sustainability; the results are accessibility and degree of permeability, Population density Built-up ratio, mixed use, urban fabric Fig. 6.

In the end, indicators were reduced from 17 to 7 indicators; the final list included mixed-use ratio, built-up area percentage of total area, degree of accessibility and permeability, population density, built-up ratio, land occupancy, and public transportation network,

\section{Round 2: transferring the final indicators to values and relative weights}

After filtering indicators of the economic sustainability model, a calculation formula for each indicator was presented for approval and to suggest values related to the degree of sustainability, as to formulate SUE model (Table 3).

\section{Results of the value setting}

Results of the value setting and relative weights are shown in Table 4.

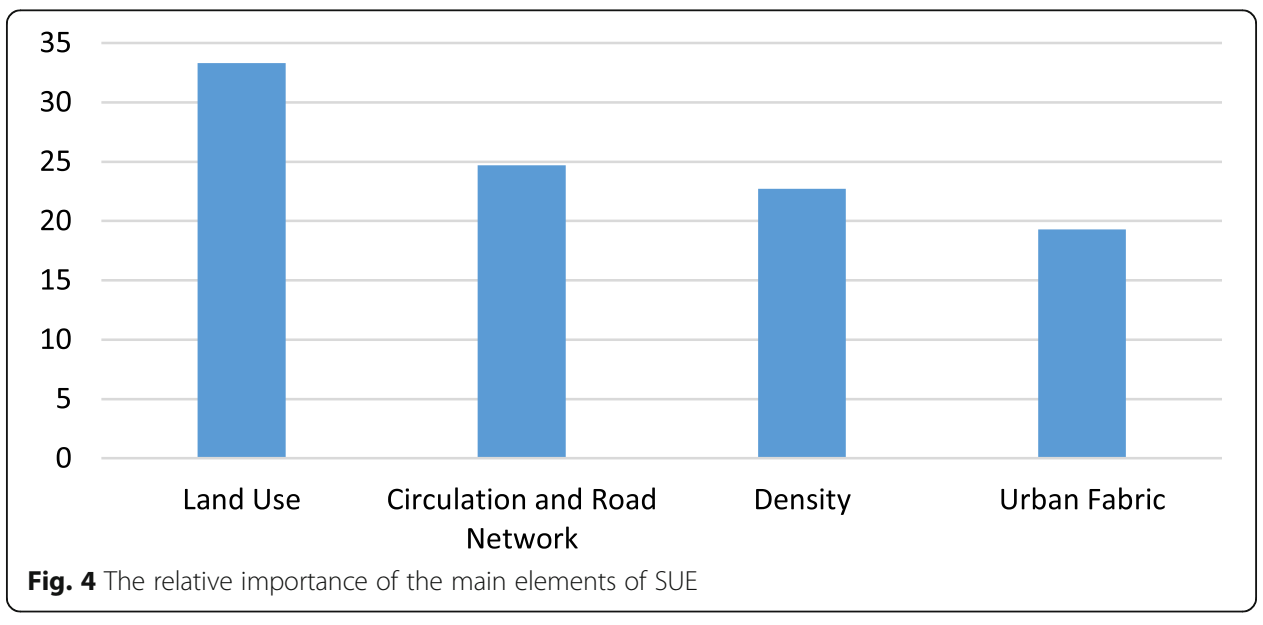




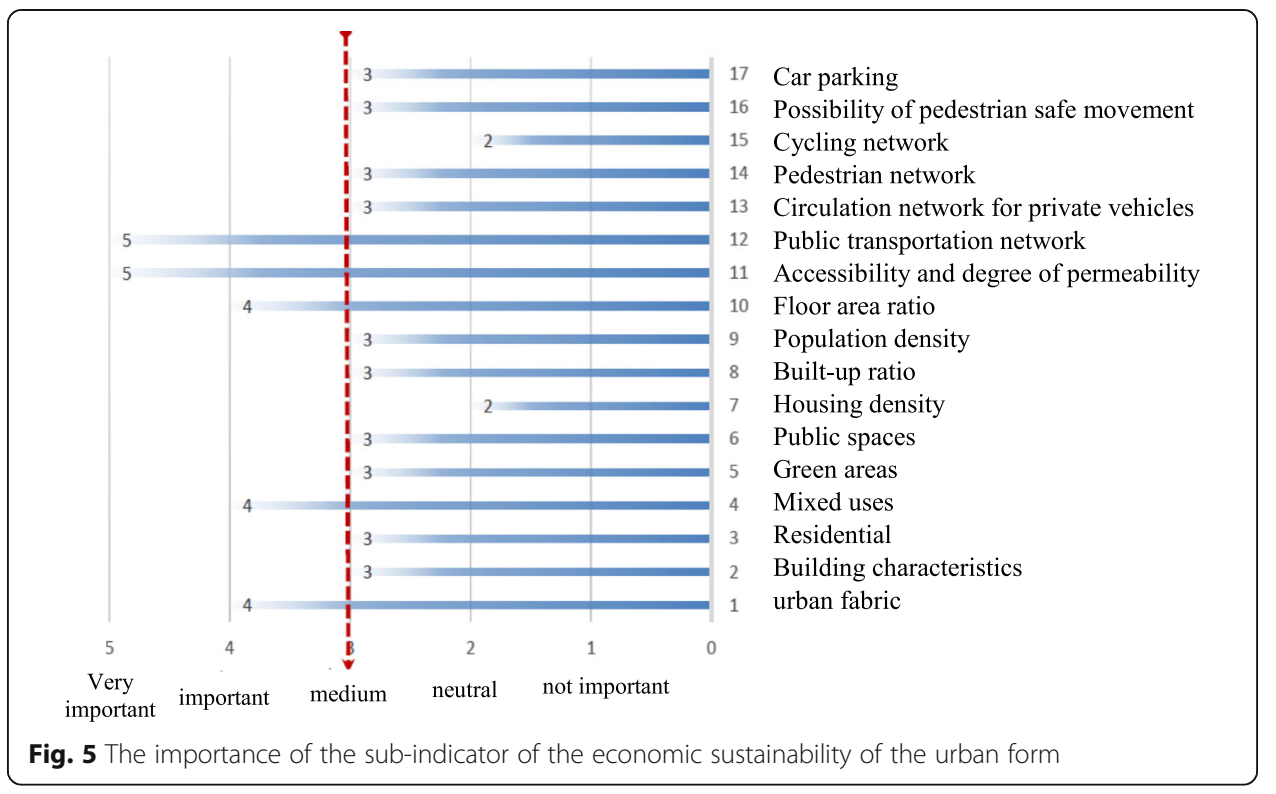

\section{Indicator 1: built-up to total space ratio (solid and void)}

There was broad consensus on the values (more than1:1 sustainable/1:0.5 partially sustainable, less than 1:0.5 unsustainable) reaching $82 \%$, while $12 \%$ suggested lower values.

\section{Indicator 2: mixed-use ratio}

There was a broad consensus also on the value of this indicator (more than $80 \%$ sustainable $/ 50-80 \%$ partially sustainable, less than $50 \%$ unsustainable), reaching $82 \%$, while $12 \%$ saw to decrease the percent.

\section{Indicator 3: built-up ratio}

Most experts agreed on the value of this indicator (less than 50\% sustainable/50-80\% partially sustainable, more than $80 \%$ unsustainable). It reached $91 \%$, while $9 \%$ suggested increasing the present to $100 \%$. Moreover, experts confirmed that these values are correlated with users' socio-economic states.

\section{Indicator 4: population density}

Experts' opinions on this indicator varied, as 64\% agreed with the value (more than 300 $\mathrm{p} /$ acre sustainable/300-150 p/acre partially sustainable, less than $150 \mathrm{p} /$ acre unsustainable), 36\% expressed the possible conflict between achieving this indicator with the rest of the other indicators, as well as respecting the difference in values between different areas.

\section{Indicator 5: floor area ratio}

Ninety-one percent suggested the same value (more than 4 sustainable/4-2 partially sustainable, less than 2 unsustainable). Whereas $9 \%$ confirmed the importance of considering the characteristics of the area, especially if it has a unique nature or value. 


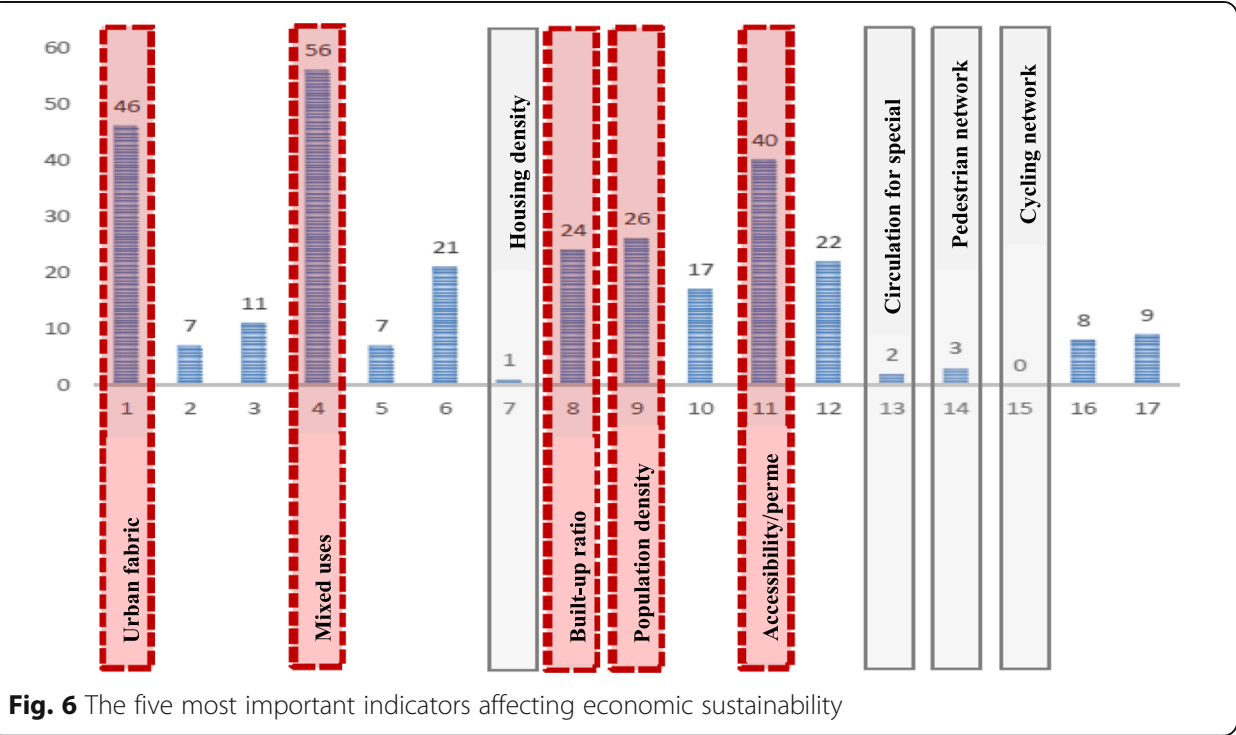

\section{Indicator 6: degree of accessibility}

All experts agreed on the value to evaluate this criterion (more than0.6 sustainable/ 0.6-0.4 partially sustainable, less than 0.4 unsustainable).

\section{Indicator 7: public transportation}

Eighty-two percent suggested values (more than 25\% sustainable/10-25\% partially sustainable, less than $10 \%$ unsustainable), whereas $18 \%$ expressed their concern regarding the ability to apply such an indicator in Egypt since there is a shortage of public transportation.

As for the relative weights, experts expressed that mixed-use and the degree of accessibility should be assigned the highest relative weight; on the other hand, the floor area ratio should be the less weight.

\section{Discussion}

The research results indicate that not all international indicators are considered important in achieving economic sustainability in the Egyptian context. Urban planners and economy experts suggest alterations are needed to transformer the current practice resulting in unsustainable residential projects/districts. Such alterations seek to attain highly mixed lands use, efficient public transportation, and high accessibility. When revising the residential areas that have grown organically named by informant settlements, it is found that residents created these three factors by transforming ground floors to retail shops and services and introducing private-owned transportation to enhance accessibility. However, in informal settlements, other indicators supporting a better quality of life are missing. Such insights can guide planners in producing more economics sustainable comminutes where finical cost is optimized and social/environmental benefits are reached. Nevertheless, this study has its limitation as not investigating the impact of location, residents' socio-economic standard, cultural roots, land value, and unique natural resources on the evaluation of economic sustainability indicators rank. 


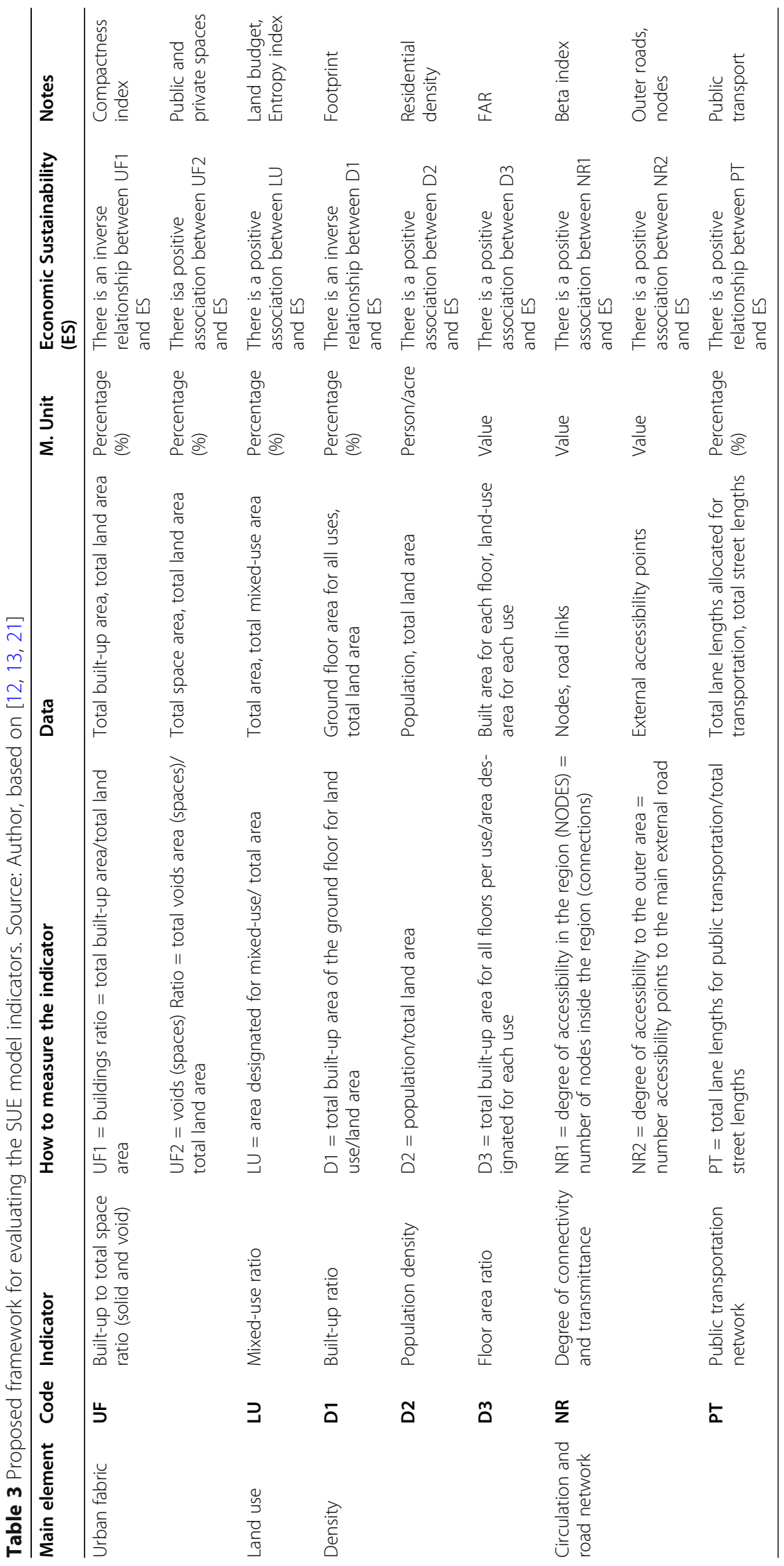


Table 4 Values assigned by experts for each economic sustainability indicator and relative weight

\begin{tabular}{lllll}
\hline Indicators & Sustainable & $\begin{array}{l}\text { Partly } \\
\text { sustainable }\end{array}$ & Unsustainable & $\begin{array}{l}\text { Relative } \\
\text { weights }\end{array}$ \\
\hline $\begin{array}{l}\text { * Built-up to total space ratio } \\
\text { (S\&V) }\end{array}$ & More than 1:1 & $1: 1$ to 1 & Less than 0.5:1 & 10 \\
* Mixed-use ratio & More than 80\% & $50-80 \%$ & Less than 50\% & 25 \\
* Built-up ratio & Less than 50\% & $50-80 \%$ & More than $80 \%$ & 10 \\
*Population density & More than 300 p/ & $30--150$ p/acre & Less than 150 p/ & 10 \\
& acre & & acre & \\
* Floor area ratio & More than 4 & $4-2$ & Less than 2 & 8 \\
*Degree of accessibility & More than 0.6 & $0.6: 0.4$ & Less than 0.4 & 17 \\
*Public transportation & More than 25\% & $10-25 \%$ & Less than 10\% & 20 \\
\hline
\end{tabular}

\section{Conclusion}

This paper introduced a model to evaluate the extent to which an urban form is economically sustainable. Economic sustainability is not only concerned with revenue, but also it considers social and environmental aspects in assessing the financial gain. Twenty-five urban planning/design and economy experts were interviewed, and they filtered 17 indicators to seven representing (SUE) model. They began by ranking four indicators affecting the urban form economic sustainably. Land use scored the highest value, then follow densities and circulation networks, finally, the urban fabric. Experts explained that mixed-use is essential in Egyptian housing projects as it increases accessibility to services, especially daily ones and workplaces; furthermore, it is consistent with the Egyptian culture. Additionally, high densities allow providing services and transport economically; therefore, these two items should be implemented in housing projects; however, the socio-economic standard of residents should be considered to determine the percent of mixing and the density. This is consistent with the compact city notion that it is considered economically sustainable. It promotes relatively high residential density with mixed land uses, an efficient public transport system, encourages walking and cycling, and opportunities for social interaction.

As for the sub-indicators, results show that the most five most influential indicators affecting economic suitability are the percent of mixed uses, the urban fabric, the degree of connectivity and permeability, the population density, and building ratio. Results show that connectivity and high densities are important in the Egyptian context to achieve higher economic sustainability. In contrast, the minor impact indicators are the cycling network, unit density, the network of private vehicles, and pedestrian paths. It is noted that cycling, green spaces, less parking, and fewer streets for traffic were excluded due to its unfamiliarity in the Egyptian context, which needs to be examined in residential projects to explore their societal acceptance and their impact on economic sustainability since they are a common practice internationally as in Amsterdam City for instance. Setting values for each sub-indicator was an attempt to guide planners when evaluating residential projects in the design phase. The evaluation would help in developing the project to ensure achieving the highest possible levels of economic sustainability. It is expected that applying the SUE model would save unnecessary costs and shift the Egyptian housing projects towards a greener approach fulfilling a better quality of life. 


\section{Appendix}

Experts' questionnaire

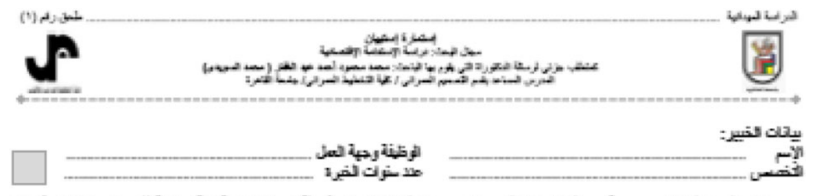

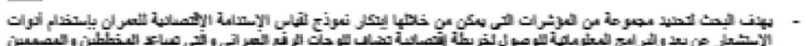

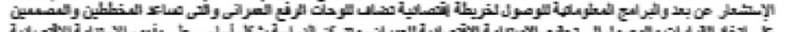

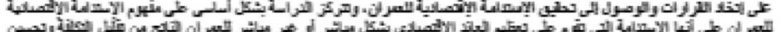

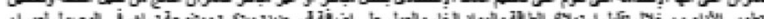

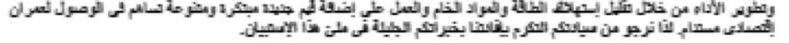

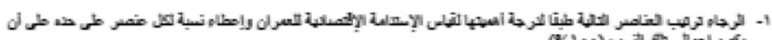

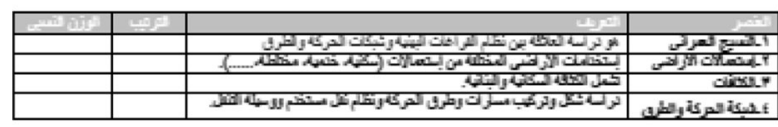

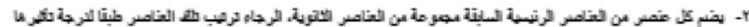

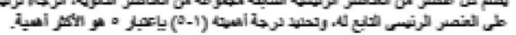
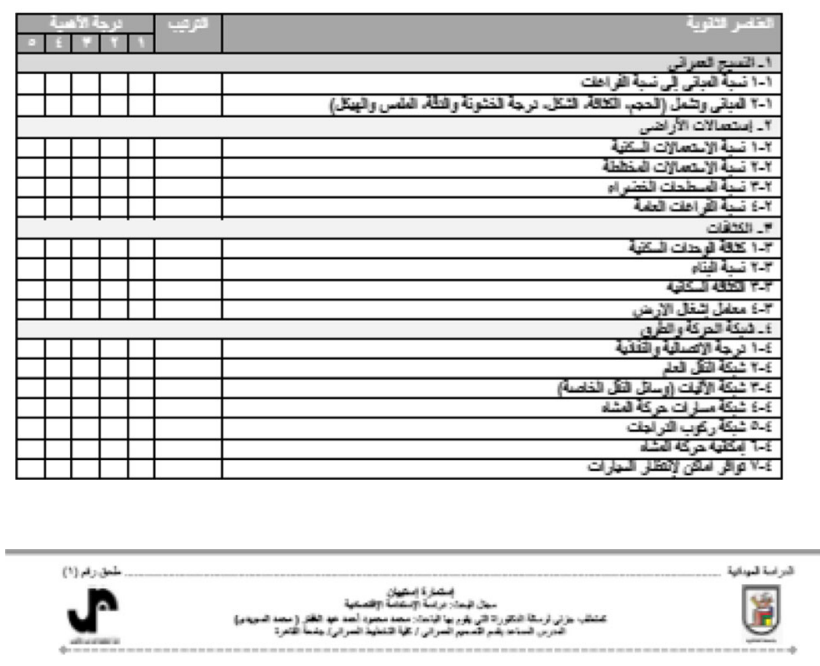

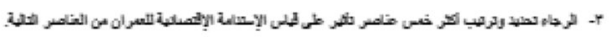

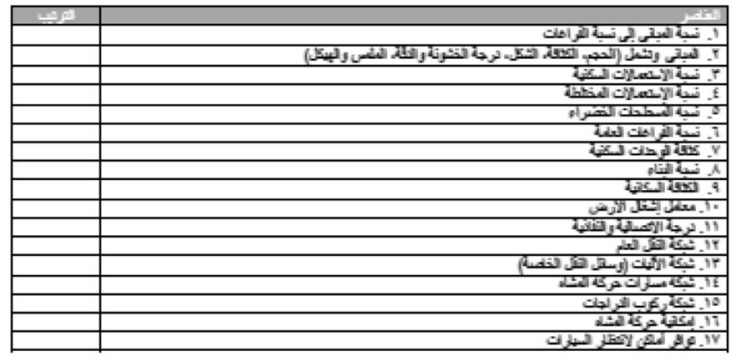

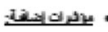

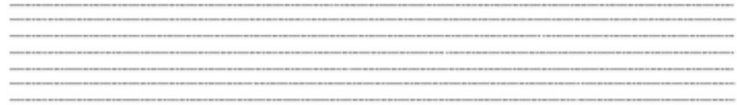

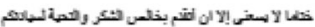




\begin{abstract}
Abbreviations
SUE model: Sustainable urban economy model; UN: United Nations; UAE: United Arab Emirates; UK: United Kingdom; Leed: Leadership in Energy and Environmental Design; Breeam: Building Research Establishment Environmental Assessment Method; Casbee: Comprehensive Assessment System for Built Environment Efficiency; PCRs: Primary Care Reimbursement Service; Green Star: Green Building Council of Australia; Dgnb: The German Sustainable Building Council; Gprs: General Packet Radio Service; SPSS: Statistical Package for the Social Sciences
\end{abstract}

\title{
Acknowledgements
}

We acknowledge all expects who contributed to the research.

\section{Authors' contributions}

The manuscript was the work of MM and NA. MM made a substantial contribution to the conception, acquisition, analysis of data, and drafted the work. NA made substantial contributions to the design of the work, interpretation of data, and substantively revised it. All authors have read and approved the manuscript. Authors are personally accountable for their contributions and the integrity of all parts of the work, they both investigated, resolved the concepts, and the resolution is documented in the literature.

\section{Funding}

We declare that we did not receive any fund from any organization during this research.

\section{Availability of data and materials}

Data were gathered by interviews (first hand data) and international literature.

\section{Declaration}

\section{Competing interests}

Both authors declare that they have no competing interests.

Received: 15 June 2021 Accepted: 4 October 2021

Published online: 19 November 2021

\section{References}

1. UNEP, https://www.undp.org/content/undp/en/home/sustainable-development-goals/goal-11-sustainable-cities-andcommunities.html (Accessed 25 Mar 2021).

2. Samaha A (2005) The role of government policies in achieving sustainable development of urban settlements in the Arab Republic of Egypt, Low-Cost Building Systems and Patterns in Urban Settlements, The General Organization for Housing and Urban Development, The Hashemite Kingdom of Jordan

3. Wu X, Zhi Q (2016) Impact of shared economy on urban sustainability: from the perspective of social, economic, and environmental sustainability. Energy Procardia 104:191-196. https://doi.org/10.1016/j.egypro.2016.12.033

4. Abdel Ghaffar MM (2014) Practical tool for enhancing the economic dimension in the urban design projects, Master Thesis, Faculty of Regional and Urban Planning, Cairo University

5. Ikerd J (2012) The essentials of economic sustainability. Kumarian Press. https://www.amazon.com/Essentials-Economic Sustainability-John-Ikerd/dp/1565495160

6. Barmelgy H, Abdel GM (2014) Sustainable urban design and the fourth dimension. J Urban Res 12(2090-0694):29-45

7. Abu Dhabi Council for Economic Development, The economic vision 2030 for the Emirate of Abu Dhabi, The General Secretariat of the Executive Council,Department of Planning and Economy, Abu Dhabi. 2009.

8. Basiago A., Economic, social, and environmental sustainability in development theory and urban planning practice, the Environmentalist, 19, 145-161, 1999, 2, DOl: https://doi.org/10.1023/A:1006697118620.

9. Ivana I, Aleksandar I, Danijela A (2018) The three dimensions of sustainable development: environment, economy and society, The 18th Conference of the series Man and Working Environment, Nis, Serbia. https://www.actvet.gov.ae/en/ Media/Lists/ELibraryLD/economic-vision-2030-full-versionEn.pdf

10. Jeronen E (2020) Economic Sustainability. In: Idowu S, Schmidpeter R, Capaldi N, Zu L, Del Baldo M, Abreu R (eds) Encyclopedia of Sustainable Management. Springer, Cham

11. Ismail A (2015) "Water consumption in green community (towards a local framework for consumption efficiency standards)", Master Thesis, Faculty of Regional and Urban Planning, Cairo University

12. Gomaa AA, Mohamed SA (2017) A process of achieving urban sustainability according to manuscripts of The United nations applied on: some of the new Egyption cities. J Eng Sci 45(5):657-687. https://doi.org/10.21608/jesaun.2017.11 6861

13. Ibrahim R, Mushatat $\mathrm{S}$, Abdelmonem $\mathrm{M}$ (2016) The role of urban pattern indicators for sustainable urban forms in the developed countries a pragmatic evaluation of two sustainable urban contexts. Erbil international conference on architecture and urbanism, Erbil city

14. Ghonimi I (2017) Towards sustainable new settlements in Egypt: lessons learned from a comparison between traditional and modern settlements in Greater Cairo Region - Egypt, Journal of Sustainable Development, vol 10. Canadian Center of Science and Education, Egypt

15. Williams K, Burton E, Jenks M (2000) Achieving sustainable urban form. E \& FN. spon, London and New York

16. Lynch K (1960) The image of the city

17. Lynch K (1981) Good city form

18. Jadon S (2007) Basic concepts of urban design, a research review, ITPI journal

19. Qian Z (2008) Shaping urban form without zoning: a case study of houston, Ph.D thesis, texas a \& $m$ university

20. Dempsey N et al (2010) Elements of urban form Dimensions of the sustainable city, vol 21-51. Springer, Dordrecht. https://doi.org/10.1007/978-1-4020-8647-2_2 
21. Shawky KA (2019) The foundations of the urban formation of projects to replace informal housing areas in Egypt, Ph.D., Thesis, Faculty of Regional and Urban Planning, Cairo University

22. Ibrahim R, Abdelmonem MG, Mushatat S (2016) The role of urban pattern indicators for sustainable urban forms in the developed countries: a pragmatic evaluation of two sustainable urban contexts, Erbil International Conference on Architecture and Urbanism, Kurdistan, Iraq

23. Imam SH (2020) Privately owned public spaces and regeneration of contexts of value. J Eng Appl Sci 67(2):315-332

24. Abdel QN, El-Touni S (1997) The problem of texture and character

25. Al-Hussayen MA, Shuaibi AM (1975) Urban land utilization: case study

26. Yousry M, Mounir A, Barada A (1970) Residential complexes for factories, the housing assembly project for the workers of the Nasr Company

27. Bashendy SY (1991) Impact of transportation technology on city form, Ph.D., Thesis, Architecture Department, Faculty of Engineering, Cairo University

28. Mostafa MI (2017) The urban elements of a sustainable city architecture, Master Thesis, Faculty of Regional and Urban Planning, Cairo University

29. Ibrahim A, Alattar A (2017) Street networks between traditional and new Egyptian developments, problems and learned lessons. Proc Environ Sci 37:306-318. https://doi.org/10.1016/j.proenv.2017.03.061

30. Jabareen YR (2006) Sustainable urban forms their typologies, models, and concepts. J Plann Educ Res 26(1):38-52. https://doi.org/10.1177/0739456X05285119

31. Ibrahim A, Shaw D (2009) Egyptian compact city veracity. The fallacy and credibility of mixed use and high density for a low carbon city, Compact -City veracity, 45th ISOCARP Congress, Porto, Portugal

32. Ali EA (1976) Urban Pattern in Egypt, Master Thesis, Faculty of Engineering, Cairo University

\section{Publisher's Note}

Springer Nature remains neutral with regard to jurisdictional claims in published maps and institutional affiliations.

\section{Submit your manuscript to a SpringerOpen ${ }^{0}$ journal and benefit from:}

- Convenient online submission

$\checkmark$ Rigorous peer review

- Open access: articles freely available online

- High visibility within the field

- Retaining the copyright to your article 